University of Nebraska - Lincoln

DigitalCommons@University of Nebraska - Lincoln

10-8-1998

\title{
Apostatic selection by blue jays produces balanced polymorphism in virtual prey
}

Alan B. Bond

University of Nebraska - Lincoln, abond1@unl.edu

Alan Kamil

University of Nebraska - Lincoln, akamil1@unl.edu

Follow this and additional works at: https://digitalcommons.unl.edu/bioscibehavior

Part of the Behavior and Ethology Commons

Bond, Alan B. and Kamil, Alan, "Apostatic selection by blue jays produces balanced polymorphism in virtual prey" (1998). Papers in Behavior and Biological Sciences. 53.

https://digitalcommons.unl.edu/bioscibehavior/53

This Article is brought to you for free and open access by the Papers in the Biological Sciences at DigitalCommons@University of Nebraska - Lincoln. It has been accepted for inclusion in Papers in Behavior and Biological Sciences by an authorized administrator of DigitalCommons@University of Nebraska - Lincoln. 


\title{
Apostatic selection by blue jays produces balanced polymorphism in virtual prey
}

\author{
Alan B. Bond I,2 and Alan C. Kamil I, 2,3 \\ I. School of Biological Sciences, 2. Nebraska Behavioral Biology Group, and 3. Department of Psychology, \\ University of Nebraska-Lincoln, Lincoln, Nebraska 68588-0I I8, USA \\ Corresponding author — Alan B. Bond, email: $\underline{\text { abond@unl.edu }}$
}

\begin{abstract}
Apostatic selection, in which predators overlook rare prey types while consuming an excess of abundant ones, has been assumed to contribute to the maintenance of prey polymorphisms. ${ }^{1,2,3}$ Such an effect requires predators to respond to changes in the relative abundance of prey, switching to alternatives when a focal prey type becomes less common., ${ }^{4}$ Apostatic selection has often been investigated using fixed relative proportions of prey, ${ }^{1,6}$ but its effects on predator-prey dynamics have been difficult to demonstrate. ${ }^{7}$ Here we report results from a new technique that incorporates computer-generated displays ${ }^{8,9}$ into an established experimental system, that of blue jays (Cyanocitta cristata) hunting for cryptic Catocala moths. ${ }^{10}$ Digital prey images from a virtual population are presented to predators. The relative numbers that escape detection determine the subsequent abundance of each prey type. If apostatic selection does promote stability, the system should converge on an equilibrium in which each prey type appears at a characteristic abundance. Our results show that the detection of cryptic prey does involve apostatic selection, and that such selection can function to maintain prey polymorphism.
\end{abstract}

We began by scanning a photograph ${ }^{11}$ of the dark morph of Catocala relicta, a moth commonly preyed on by jays. Four novel morphs, moths $1-4$, were generated by random modification of this prototype, whereas moth 5 was obtained by similarly processing a photograph of $C$. retecta. The resulting digital moths were bilaterally symmetrical, roughly triangular, and disparate in appearance, at least to human eyes. They were rendered difficult to detect by presenting them on backgrounds that approximated their pixel intensities and pattern granularity (Figure 1$).{ }^{12}$

Six hand-reared blue jays with experience in similar tasks searched for prey on a computer screen in a series of discrete trials. Trials were either prey trials, with a moth overlaid on the background at a random location, or no-prey trials, with no moth present. If the bird found and pecked at a moth, it received a food reward. If not, it could proceed rapidly to the next trial by pecking a central green disk. Each bird received 36 prey trials and 84 no-prey trials per day in random order. The 216 moths exposed to potential predation each day were drawn at random without replacement from a virtual population of 240 moths. Detected moths were considered "killed" and were removed from the pool. At the beginning of the next day, the population was regenerated to 240 , maintaining the relative abundance shown by the surviving prey. Thus, each day formed a "generation," and the effects of predation were reflected in the frequency of the different morphs the following day. The only

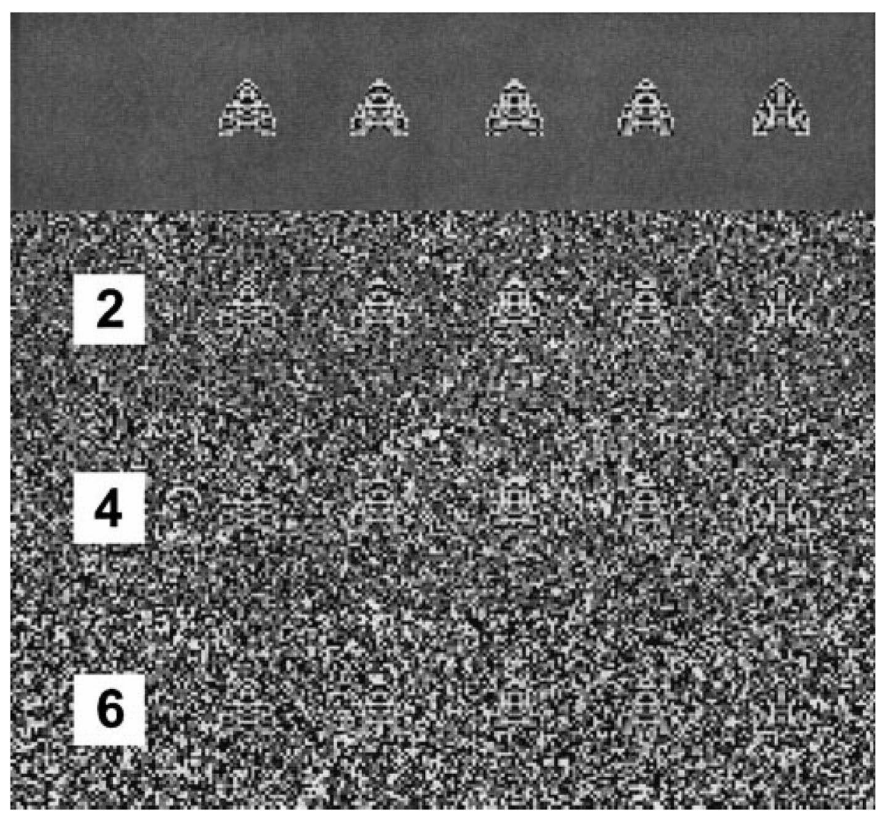

Figure I. The five types of digital moths used in these experiments (moth I to moth 5, from left to right), presented against backgrounds of three levels of crypticity to illustrate the difficulty of the detection task. When projected on a computer monitor, the images of the moths were $\sim 6 \mathrm{~mm}$ high. The image can be viewed in more detail at http://niko.unl.edu/ kamil/moths/ vpmoths.htm 
limits on free variation were the initial relative proportions of the prey morphs, which we set at the beginning of each replication, and the constraint that no morph was allowed a frequency of less than five individuals at the start of a day.

The experiment began with a founding population consisting of equal numbers of moths $1-3$. Over the subsequent 50 days, the abundance of moth 1 , the most cryptic morph, increased from its initial value to a maximum of $\sim 180$ individuals before leveling off (Figure 2a). The numbers of moths 2 and 3 , in contrast, dropped to around 30 individuals each. We then began a second replication by raising moth 2 to 180 of the 240 individuals in the population and dropping both moths 1 and 3 to 30 individuals. After 50 days, equilibrium levels similar to those in the first replication were attained (Figure 2a). We then conducted a third replication by maximizing the initial relative abundance of moth 3 . In all three replications, equilibrium population levels appeared to be attained with 30 generations, with $\sim 75 \%$ of the population consisting of moth 1 and $12.5 \%$ each of moths 2 and 3.

In these three replications, no morph ever declined to fewer than five individuals, and we never had to intervene to prevent extinction. Both population levels and detectability (Figure $2 b$ ) exhibited a slow oscillation with a period, shown by autocorrelation analysis, of about ten generations $(r=0.11, P<$ $0.04)$. For this ten-generation cycle, the mean phase difference between population numbers and detectability was $+0.3 \pi$, which indicates that peak detectability lagged behind peak population by $\sim 1.5$ generations. These results, together with the stable equilibrium that follows perturbation, indicate that negative feedback between population numbers and detectability is sustaining the polymorphism.

The functional response of a predator is the relationship between the proportion of each prey morph in the diet and the proportion available in the environment. ${ }^{13} \mathrm{~A}$ sigmoid functional response, in which the proportion in the diet is amplified at high relative abundances and diminished at low ones, is a defining criterion for apostatic selection. ${ }^{2}$ In Figure 3 we display the residuals from the expected linear function, that is, plots of the difference between proportion of each prey morph taken and proportion presented as a function of the proportion

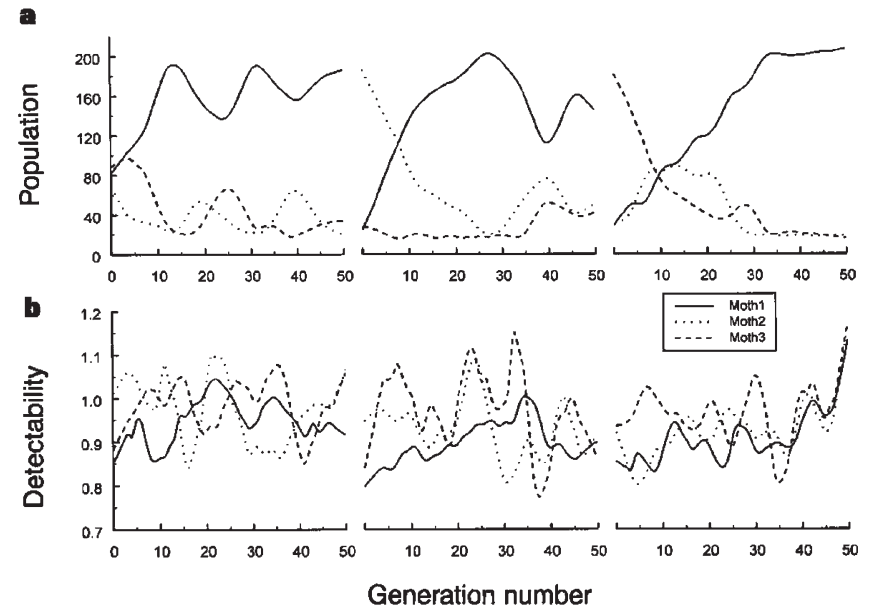

Figure 2. Population numbers and prey detectability of three prey morphs in three successive replications of the virtual prey procedure. a) Population numbers of the three morphs. Curves were smoothed with weighted least squares, using an eight-generation window. b) Prey detectability, expressed as the arcsine of the proportion of correct responses to prey trials, in the same three replications. Curves were smoothed as in $\mathbf{a}$. presented. Apostatic selection predicts that the residuals should increase with the proportion presented, corresponding to overselection at high relative abundances.

Linear regression analysis yielded significant positive slopes for all three morphs, confirming the prediction. Analysis of covariance found no significant differences among slopes. The intercept was significantly less than 0.0 only for moth 1 $(P<0.01)$, indicating that this more cryptic morph was often overlooked when it was rare. Although it is possible that these effects resulted from a simple preference for the most abundant prey, previous work has shown repeatedly that a predator's ability to detect cryptic prey varies with the encounter frequency, a phenomenon often termed "searching image." 10, $14,15,16,17$ In a separate study, jays searching for cryptic digital moths showed clear searching-image effects when presentation probabilities were manipulated systematically (A.B.B. \& A.C.K., in preparation).

At equilibrium, frequency-dependent selection should result in equal fitnesses for all morphs, ${ }^{18}$ expressed here as equal risks of detection. This provides a quantitative test of convergence to equilibrium. We eliminated oscillatory noise by extracting the linear trend of detectability as a function of generation for each morph in each replication. The predicted values for generation 0 from the trend analysis showed a far larger variance than those for generation $50(F(8,8)=4.10, P=0.03)$. Detectability values for the first three morphs thus converged over the course of each replication, confirming the approach to equilibrium.

Frequency-dependent selection should also maximize the average fitness of the prey population at equilibrium. ${ }^{18}$ We examined changes in foraging success over the course of a replication by dividing number of prey detected within each generation by total search time, summed across birds and trials. The linear trend of foraging success as a function of generation number yielded significant negative slopes for all replications (replication 1: $\beta=-0.0014, P=0.02$; replication 2: $\beta=-0.0019$, $P=0.003$; replication $3: \beta=-0.0014, P=0.014)$, reflecting the higher relative abundance of the most cryptic morph at equilibrium. By tending to search for the morph that is currently most abundant, predators improve their ability to detect that morph, maximizing their short-term foraging success. However, the long-term consequence is to generate a distribution of prey abundances that yields a significantly reduced rate of return.

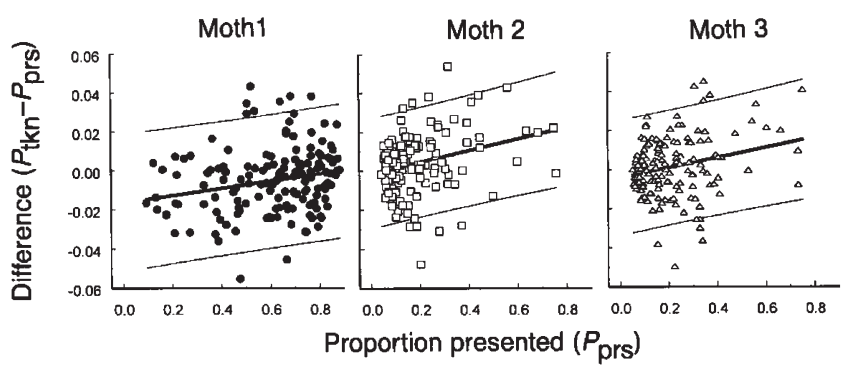

Figure 3. Functional response curves for the three morphs in the first three replications. Each data point indicates the relationship for a single daily session. The abscissa is $P_{\text {prs }}$, the proportion of prey trials that included the given moth type; the ordinate is the difference between $P_{\mathrm{tkn}}$, the proportion of that moth detected ("taken") by the birds, and the proportion presented. The regression line indicating the association between the difference and $P_{\text {prs }}$ is shown, together with its $95 \%$ confidence limits. The slopes for each prey type were: moth I, $\beta=0.018, P=0.009$; moth $2, \beta=0.030, P=0.0004$; moth $3, \beta$ $=0.026, P=0.002$. 


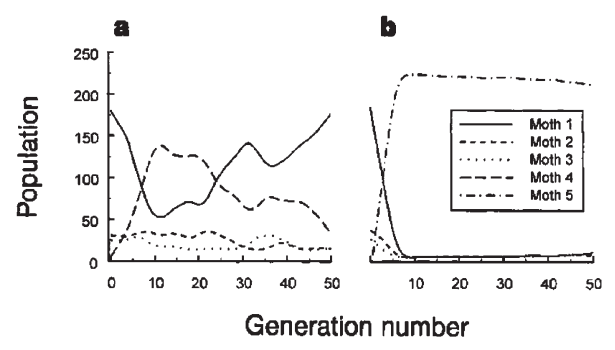

Figure 4. Population numbers of four morphs in the last two replications of the virtual predation procedure. Curves were smoothed with weighted least squares, using an eight-generation window. a) Replication 4, including moths $\mathrm{I}-3$ and moth 4 ; b)replication 5 , including moths $\mathrm{I}-3$ and moth 5 .

The strongest effects of apostatic selection should be evident with novel prey. Tinbergen ${ }^{14}$ found that insectivorous birds generally overlooked newly emergent prey until they had attained high population levels. At some point, however, the birds would start concentrating on the new prey, driving down abundance. We simulated this situation in the fourth and fifth replications. In replication 4, moths 1-3 were maintained at their proportional equilibrium abundances, and seven individuals of moth 4 were added to the population. Moth 4 was initially detected infrequently, with an average detectability in the first three generations of only 0.64. By the tenth generation, however, detectability reached levels comparable to the other three morphs, and the population of moth 4 began to decline, reaching levels similar to that of moths 2 and 3 (Figure $4 a$ ).

In replication 5, we followed the same procedure, introducing seven individuals of moth 5 , which was exceedingly difficult to detect. Moth 5 was completely overlooked until generation 7 , at which point it constituted $94 \%$ of the population (Figure $4 b$ ). One jay began feeding on moth 5 at this time, and a second started at generation 14 . Both birds rapidly increased their detectability on this morph to $0.9-1.0$. However, no other birds learned to detect moth 5, even after 50 generations and, consequently, moth 5 sustained maximal population levels through the replication (Figure $4 \mathrm{~b}$ ). The other morphs would have been driven to extinction if they had not been repeatedly brought up to the minimum of five individuals at the start of each generation.

These last results show that stable equilibrium is not an invariable result of visual search for cryptic, polymorphic prey. If the prey are too conspicuous, frequency-dependent effects will be small, and random drift will eventually result in local

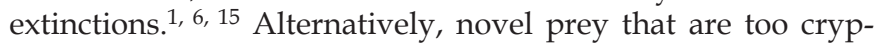
tic or predators that are too inflexible in searching strategies can apparently also result in fixation of more cryptic morphs. ${ }^{3}$ To our knowledge, the dynamics of balanced polymorphism, although long established in theory, have never before been demonstrated empirically in a predator-prey system. Because the virtual prey technique incorporated the reciprocal interaction between the predator's searching behavior and the relative abundance of different prey morphs, we have been able to show that changes in prey detection alone can produce stability and can maintain prey polymorphism.

\section{Methods}

Stimuli. The initial digital image was reformed into the resting pose that was typical of the species, with the head orientated upwards, exposing only the cryptic upper surfaces of the forewings. It was then reduced to fit in a sixteen-pixel square, histogram-normalized, and converted to grey-scale at SVGA resolution $(640 \times 480 \times 64$ levels of grey). Corresponding pixels were averaged about the central axis to ensure bilat- eral symmetry. Novel morphs were generated from the initial prototype by inverting the brightness values of a randomly selected subset of $16 \%$ of the wing pixels. Cryptic backgrounds were generated based on the pooled frequency distribution of brightness values from the moth images. This distribution was roughly bimodal: the highest concealing effect, for human evaluators, was obtained with equal-variance peaks with modes of six and 56. To vary task difficulty, we created backgrounds that were random mixtures of pixels from this bimodal distribution and another, unimodal distribution centered around 30, against which the digital moths seemed far more conspicuous. The difficulty level was coded as an integer, with 1 indicating that $10 \%$ of the pixels came from the bimodal distribution, 2 meaning $20 \%$ bimodal, and so on. In the final step, a fractal texture was imposed on the background, increasing the granularity to correspond more closely to the patterns exhibited by the digital moths.

Subjects and procedures. The blue jays, captured as nestlings and handreared, had all participated in visual detection experiments, including studies using the same backgrounds and similar prey stimuli. Each trial began by displaying two $9.5 \times 13 \mathrm{~cm}$ fields of cryptic background with a $2.7-\mathrm{cm}$ green disk between them. Equal numbers of each of five levels of background difficulty (4-8 on the scale shown in Figure 1) were used each day. The screen was surrounded with an infrared touch frame; a single peck to the screen ended the trial and caused the display to go blank. During a prey trial, a peck directed at the moth was rewarded with a piece of mealworm, and a new trial followed after $12 \mathrm{~s}$. During either prey or no-prey trials, pecks to the green disk reduced the time to the next trial to $6 \mathrm{~s}$, whereas pecks to the background away from any moth image increased it to $30 \mathrm{~s}$. Erroneous responses to the background, which were uncommon, were thus discouraged by long delays before beginning the next trial.

\section{References}

I. Allen, J.A. Frequency-dependent selection by predators. Phil.Trans. R. Soc. Lond. B 319, 485-503 (1988).

2. Clarke, B. C. in Taxonomy and Geography (ed. Nichols, D.) 47-70 (Systematics Association, Oxford, 1962).

3. Clarke, B. C. The evidence for apostatic selection. Heredity 24, 347-352 (1969).

4. Murdoch, W. W. Switching in general predators: experiments on predator specificity and stability of prey populations. Ecol. Monogr. 39, 335-354 (1969).

5. Murdoch, W.W. \& Oaten, A. Predation and population stability. Adv. Ecol. Res. 9, I-I3I (1974).

6. Cooper, J. M. Apostatic selection on prey that match the background. Biol. J. Linn. Soc. 23, 22I-228 (1984).

7. Cooper, J. M. \& Allen, J. A. Selection by wild birds on artificial dimorphic prey on varied backgrounds. Biol.J. Linn. Soc. 5 I, 433-446 (1994).

8. Glanville, P.W. \& Allen, J. A. Protective polymorphism in populations of computer-simulated moth-like prey. Oikos 80, 565-57I (1997).

9. Plaisted, K. C. \& Mackintosh, N. J.Visual search for cryptic stimuli in pigeons: implications for the search image and search rate hypotheses. Anim. Behav. 50, 1219-1232 (1995).

10. Pietrewicz, A. T. \& Kamil, A. C. Search image formation in the blue jay (Cyanocitta cristata). Science 204, 1332-1333 (1979).

II. Sargent, T. D. Legion of Night:The Underwing Moths (Univ. Massachusetts Press, Amherst, 1976).

12. Endler, J. A. Progressive background matching in moths, and a quantitative measure of crypsis. Biol.J. Linn. Soc. 22, |87-23| (1984).

13. Holling, C. S. The functional response of predators to prey density and its role in mimicry and population regulation. Mem. Entomol. Soc. Can. 45, I60 (1965).

I4. Tinbergen, $N$. The natural control of insects of pinewoods I. Factors influencing the intensity of predation by songbirds. Arch. Néerland. Zool. 13, 265343 (1960).

15. Bond, A. B. Visual search and selection of natural stimuli in the pigeon: the attention threshold hypothesis. J. Exp. Psychol. Anim. Behav. Process. 9, 292 306 (1983).

16. Blough, P. M. Selective attention and search images in pigeons. J. Exp. Psychol. Anim. Behav. Process. 17, 292-298 (1991).

17. Langley, C. M. Search images: selective attention to specific visual features. J. Exp. Psychol.Anim. Behav. Process. 22, 152-163 (1996).

18. Wallace, B. Basic Population Genetics 229-230 (Columbia Univ. Press, New York, 198I). 